The Federal Reserve BanK of Kansas City Research Working Papers

Is Optimal Monetary Policy Always Optimal?

Troy Davig and Refet S. Gürkaynak July 2015 RWP 15-05 


\title{
Is Optimal Monetary Policy Always Optimal?*
}

\author{
Troy Davig ${ }^{\dagger} \quad$ Refet S. Gürkaynak $k^{\ddagger}$ \\ First Draft: December 2014 \\ This version: July 30, 2015
}

\begin{abstract}
No. And not only for the reason you think. In a world with multiple inefficiencies the single policy tool the central bank has control over will not undo all inefficiencies; this is well understood. We argue that the world is better characterized by multiple inefficiencies and multiple policy makers with various objectives. Asking the policy question only in terms of optimal monetary policy effectively turns the central bank into the residual claimant of all policy and gives the other policymakers a free hand in pursuing their own goals. This further worsens the tradeoffs faced by the central bank. The optimal monetary policy literature and the optimal simple rules often labeled flexible inflation targeting assign all of the cyclical policymaking duties to central banks. This distorts the policy discussion and narrows the policy choices to a suboptimal set. We highlight this issue and call for a broader thinking of optimal policies.
\end{abstract}

JEL Classification: E61, E52, E58, E02

${ }^{*}$ We thank Ragna Alstadheim, Jordi Gali, Özer Karagedikli, Athanasios Orphanides, Jaume Ventura, John Williams, Seçil Yıldırım participants of conferences at the Reserve Bank of New Zealand and Central Bank of Azerbaijan for comments. The views expressed herein are those of the authors and do not necessarily represent those of the Federal Reserve Bank of Kansas City or the Federal Reserve System.

${ }^{\dagger}$ Federal Reserve Bank of Kansas City, Kansas City, MO 64198, USA. troy.davig@kc.frb.org.

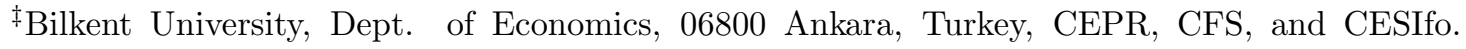
refet@bilkent.edu.tr. 


\section{Introduction}

The debate on optimal policy mix is old and the current literature on welfare-based optimal monetary policy is extensive. But these two literatures are fundamentally different in that optimal monetary policy, as the name suggests, is an exclusively monetary policy question, leaving no room for a policy mix. Sometime between the 1960s and the period's Mundell-Fleming model that allows asking fiscal and monetary policy questions, to the 1990s and the current optimal monetary policy questions, many academic economists and policymakers coalesced around the view that monetary policy is more nimble and hence better suited to address cyclical issues.

The focus on monetary policy has had the unintended consequence of justifying the treatment of central banks as residual claimants of policy. That is, on top of their usual mandate of controlling inflation, central banks are charged with all types of cyclical policy duties not completely addressed by other policymakers. These range from unemployment and financial stability to exchange rates and current account deficits, even to economic inequality. The literature by and large views this favorably, as central banks take the actions of other policymakers as given and internalize social welfare. In this approach to optimal monetary policy, any economic variable that enters the welfare function and is affected by interest rates receives a non-zero weight in the optimal policy rule. This, in turn, justifies using monetary policy to address that variable in practice.

Monetary policy trying to address too many objectives is hampered by two types of problems in replicating the efficient allocation. The first one is well known: a single policy instrument cannot be used to achieve multiple independent objectives. This static concern is of course valid. But we also highlight a second, strategic problem that arises in the presence of multiple policymakers.

To the extent that other policymakers have competing objectives, such as the fiscal policymaker having a bias for increasing (or reducing) spending or the financial regulator having a preferred level of regulation, they will engage in policies that worsen the policy trade-offs for the central bank if they do not have to internalize outcomes. Asking only the optimal monetary policy question assigns the full burden of welfare maximizing policy to the central bank and effectively absolves the other policymakers 
of the consequences of their actions. In that case, they will engage in behavior that will be welfare reducing and cannot be undone by monetary policy.

Our concern is that, especially in the last few years, central banks have become policymakers of last resort. Many central banks around the world try to control inflation while also behaving as residual claimants of all macroeconomic policies. Unemployment or capital flow problems not addressed by fiscal policymakers, macroprudential concerns not addressed by bank regulators and many other important policy issues have become issues that central bankers talk about and act on. These issues are certainly important, but central banks that effectively take them on as additional mandates may not be socially optimal, as the policymakers better suited to address various issues may be even less likely to act when the central bank is seen as the agent responsible for the outcome.

This paper will therefore highlight the inefficiencies inherent in treating central banks as policymakers of last resort, drawing attention to the facts that central banks cannot effectively address all inefficiencies, and also that there will be more inefficiencies if other policymakers do not have to internalize the consequences of their actions.

\section{The Only Game in Town}

The literature on model consistent welfare functions and optimal policy that maximizes welfare begins with the seminal work of Rotemberg and Woodford (1997). In almost all of this literature, the policymaker is the central bank that sets the interest rate to maximize welfare. Fiscal policy enters the picture only to the extent that the steady state inefficiency due to monopoly power is corrected by a lump sum tax and a subsidy so that welfare is analyzed around an efficient steady state. Thus, fiscal policy is absent from cyclical policy analysis.

Unsurprisingly, in optimal monetary policy problems the interest rate responds to all welfare relevant variables in the model. Hence, the literature finds that optimal policy is to set interest rates to control a combination of inflation and the output gap (Rotemberg and Woodford (1997), Giannoni and Woodford (2002)) as well as exchange rates (Corsetti, Dedola and Leduc (2010)), house prices Adam and Woodford (2013)), macroprudential concerns (Smets (2014)), asset prices (Gali (2014)), and so 
on. These papers are correct: if the only available policy tool is the interest rate, it should be set to maximize social welfare and will therefore respond to all distortions that are affected by monetary policy.

This result is implicit in the modeling choice that asks the optimal monetary policy question, rather than the optimal policy question. In actual policy analysis this corresponds to the answer of the question "how should monetary policy behave if no other policymaker is doing anything?" and indeed, there are times when this is the relevant question. In the recent Global Financial Crisis and subsequent Great Recession, many fiscal authorities either did not provide much stimulus or pursued contractionary policies due to factors such as political paralysis or policymaker preferences for small governments and low debt stocks. In these cases, central banks began to put more emphasis on output gap or employment to pick up the policy slack and were subsequently criticized for not doing enough.

A particularly striking example of a central bank minding many competing objectives is Sweden, where monetary policy was used to counter household leveraging, which required rising interest rates at a time of inflation below target and unemployment above NAIRU (Svensson $(2014))$. The question is not whether fast leveraging is a policy concern-it may well be- but rather whether it should be a monetary policy concern. To the extent that higher interest rates lower debt to income ratios, which Svensson argues is not the case in Sweden, monetary policy can be used to lower leverage but is a roundabout way that creates steep trade-offs. It may be more efficient to use financial regulation to impose lower loan to value rates, for example. But if such regulation is slow to be enacted, central banks often rise to the occasion and use interest rates, perhaps because they are used to doing cyclical policy and can act fast.

The Central Bank of Turkey (CBRT) similarly took on additional mandates in multiple instances in the past few years (Akkaya and Gürkaynak (2012)). An inflation targeter with lexicographic mandates that requires the inflation target to be met before it can aid the government in other policy pursuits, the CBRT lowered policy rates to discourage short term currency flows and help promote exports to aid in closing the large current account deficit, at a time when inflation was above the target. CBRT now mentions financial stability, growth, and exchange rates as well as inflation when talking about policy objectives. Gürkaynak et al. (2015) show that 
at least partly as a result, the central bank's reaction function has changed and it is not the inflation fighter it used to be. Currency flows, exports and current account deficit are of course all important policy objectives that affect social welfare. But have these become relevant for monetary policy because other policymakers are slow or hesitant to do their jobs or have competing objectives, or are other policymakers pursuing competing objectives precisely because CBRT is taking the blame for the undesirable outcomes?

The fact that central banks often have to sacrifice their inflation goals to pursue other objectives is well known. Indeed, a substantial chorus of central bankers point to the limits and challenges that arise when monetary policy takes on the role of the residual claimant of macropolicy. Orphanides (2013) discusses the burdens on monetary policy as central banks expand their focus and objectives to include employment, public-sector balance sheet support and financial stability. While monetary policy can make attempts to address such issues, other tools are often more appropriate. Inflation targeting frameworks, instead, may prove effective at limiting central bank excursions into areas where the efficacy of interest rate policy is quite limited, particularly when compared to instruments available to other policy authorities. Although a primary motivation of the inflation targeting framework was adoption of a nominal anchor, Bernanke and Mishkin (1997) describe the benefits more precisely as bringing coherence, transparency and discipline to monetary policy. Disciplining the central bank to focus on its narrow mandate is indeed important.

The main point we are making in this paper is that monetary policy is not the only game in town and behaving as if it is creates more costs than may be commonly perceived. When the central banks take on more policy mandates either explicitly and willingly or implicitly and out of necessity, they are the ones to be criticized when those objectives are unmet. In that case, other policymakers who wield instruments that can more effectively address those objectives have less incentive to actively use these instruments-they no longer internalize the cost of missing targets. This makes the trade off for central banks even worse.

One way to re-think the examples presented above is through policymaker incentives. As long as the ECB is seen as the only policymaker in the euro area and is blamed for its ills, fiscal authorities in member countries do not have the right incentive to pursue coordinated fiscal policies that will help prop up demand, or to engage 
in structural reforms that are costly in the short run. Or in Turkey, the government can continue to pursue expansionary policies, stoking currency inflows and boosting imports, while blaming the central bank for not doing enough to counter these as well as for missing the inflation target (Gürkaynak (2015)).

While the literature on optimal monetary policy has been instrumental in analyzing normative questions, it also gave theoretical credence to the idea that central banks are default cyclical policymakers and would pick up any policy slack. In a vicious cycle, policymakers' belief that "monetary policy is more nimble and is therefore more appropriate for cyclical policy" and the literature's theoretical finding that "optimal monetary policy should address all cyclical concerns" have fed off of each other, turning monetary policy into the residual claimant of all macroeconomic policy.

It is, however, important to remember that we observe equilibrium outcomes. Monetary policy has to be more nimble because it is used for cyclical dampening purposes while fiscal (or other) policies can be slow because no one questions why they are not designed and implemented faster. This is an artefact of the current policy landscape and is a consequence of the implicit distribution of social loss among various policymakers.

Clearly, it matters how the social welfare function is translated into mandates for multiple policymakers. With a single policymaker, assuming away time inconsistency problems, giving that policymaker maximization of social welfare as the mandate will be optimal. However, with multiple policymakers, if one is maximizing social welfare and others have free hands in pursuing their alternative goals, what will be the welfare consequences? This question does not explicitly arise in the literature, although it is of first order importance. Below we present a simple model to answer it and highlight our concern about treating central banks as the default cyclical macroeconomic policymaker.

\section{General Framework}

A few modifications to the benchmark New Keynesian model can highlight the tension between policymakers and the temptation for monetary policy to assume primary responsibility for mitigating the cycle. First, the framework requires a policy instrument 
that is under the control of a non-monetary authority and enters the forward-looking Phillips curve as follows

$$
\pi_{t}=\beta E_{t} \pi_{t+1}+\kappa x_{t}+\psi z_{t}+\varepsilon_{t}
$$

where $\pi_{t}$ represents the log deviation of inflation from its target, $x_{t}$ is the log deviation of output from its level under flexible prices, and $\varepsilon_{t}$ is a markup shock. The novel aspect of the setup is $z_{t}$, which represents a policy instrument outside of the control of the central bank. As an example, the following section incorporates a value-added tax applied to the monopolistically competitive goods producers within an otherwise standard New Keynesian framework ${ }^{1}$

The second modification includes an assumption that a monetary and a nonmonetary authority set their policy instruments independently. The following section uses the example of a monetary and fiscal authority, exploring cases when each is assigned objectives that maximize social welfare, as well as cases when each pursues different objectives. The example assumes the fiscal authority takes the monetary policy reaction function as given and sets the tax rate in a strategic manner. That is, when setting the tax rate, the fiscal policymaker incorporates, or exploits, the systematic response of monetary policy in a way that aids in achieving its objectives. In contrast, the central bank takes the tax rate as a given exogenous factor, so does not incorporate into its optimization problem how tax rates adjust to monetary policy.

In this small model, households' behavior follows the standard New Keynesian formulation given by the linearized consumption Euler equation

$$
x_{t}=E_{t} x_{t+1}-\sigma^{-1}\left(i_{t}-E_{t} \pi_{t+1}\right)+u_{t},
$$

where $i_{t}$ is the nominal interest rate and $u_{t} \sim N\left(0, \sigma_{u}^{2}\right)$ can represent shocks to, for example, government purchases or the household's discount rate.

\footnotetext{
${ }^{1}$ See Krause and Lemke (2005) for a similar interpretation regarding the value-added tax.
} 


\section{Achieving the Social Optimum via "Correct" Policy Mandates}

To illustrate these issues in the context of separate monetary and fiscal authorities, consider a setting with the social loss function given by

$$
L_{t}^{S}=E_{t} \sum_{i=0}^{\infty} \beta^{i}\left(\pi_{t+i}^{2}+\lambda^{S} x_{t+i}^{2}\right) .
$$

In terms of the pricing behavior, the framework resembles a standard New Keynesian model, except a value-added tax imposed on producers introduces an additional term into the Phillips curve,

$$
\pi_{t}=\beta E_{t} \pi_{t+1}+\kappa x_{t}+\psi \tau_{t}+\varepsilon_{t}
$$

where $\tau_{t}$ is the instrument of the fiscal authority and $\varepsilon_{t} \sim N\left(0, \sigma_{\varepsilon}^{2}\right)$ reflects a shock to the monopolistically competitive firms' markup $\bigsqcup^{2}$ Household consumption follows (2).

We can now think about welfare under two different policy mandates for the central bank. The first requires exclusive focus on inflation, so the loss specific to the central bank becomes

$$
L_{t}^{C B}=E_{t} \sum_{i=0}^{\infty} \beta^{i}\left(\pi_{t+i}^{2}\right) .
$$

In this case, monetary policy can offset any demand-side disturbance and adjust the output gap in a manner that perfectly aligns inflation with its target. The solution yields the following instrument rule

$$
i_{t}=\frac{\sigma}{\kappa}\left(\varepsilon_{t}+\psi \tau_{t}\right)+\sigma u_{t}
$$

and results in the central bank meeting its mandate exactly by adjusting the output gap according to $x_{t}=-\frac{1}{\kappa}\left(\psi \tau_{t}+\varepsilon_{t}\right)$. This approach, however, is not the social optimal, since welfare may be improved if the central bank is given the social loss function

\footnotetext{
${ }^{2}$ Details concerning equation (4) and derivations of all further results discussed in the main text are relegated to the appendix.
} 
(3) as the mandate. In this case, adopting the social loss yields the following rule

$$
i_{t}=\frac{\kappa \sigma}{\kappa^{2}+\lambda^{S}}\left(\varepsilon_{t}+\psi \tau_{t}\right)+\sigma u_{t},
$$

highlighting how the response to the supply-side disturbances declines as weight on output gap stabilization, $\lambda^{S}$, increases.

When monetary policy aligns its objectives with society, neither objective is exactly met, but social welfare is maximized. This is a manifestation of the general critique of giving too many jobs to central banks. With a single policy tool, the central bank cannot completely address multiple objectives. This standard dictum of optimal control theory appears in the central banking literature repeatedly.

It is, however, the case that the central bank has indeed maximized social welfare subject to its available policy tool and economic environment. This too is a standard finding in the optimal policy literature. As in the case above, where the divine coincidence does not hold in a world with cost-push shocks, the central bank faces a trade-off between various objectives. The received wisdom is that confronting this trade-off is still the optimal policy.

We disagree. Our disagreement is primarily because there exist first best tools of addressing various inefficiencies in the economy and the interest rate is rarely, if ever, that tool for inefficiencies other than welfare losses from inflation. Monetary policy can certainly support demand and thereby aid in moving economies towards full employment. Such efforts, however, often lead other policy authorities to neglect implementing policies using more appropriate instruments. Efforts by monetary policy to compensate for the lack of urgency on the part of other policymakers may even create vulnerabilities, such as in the financial system, that ultimately prove counterproductive to achieving the social optimum.

To illustrate how a central bank's focus on objectives other than price stability can distort the incentives of other policymakers, consider the choice of $\tau_{t}$ under the control of a fiscal authority. Label the loss function for this authority $F$ and assume it takes the central bank's reaction function as given. If the central bank follows a strict inflation targeting regime, as in (5), with the fiscal authority minimizing the 
loss due to output gap fluctuations

$$
L_{t}^{F}=E_{t} \sum_{i=0}^{\infty} \beta^{i}\left(x_{t+i}^{2}\right),
$$

then the tax rate is set according to

$$
\tau_{t}=-\frac{\varepsilon_{t}}{\psi}
$$

directing it to use the instrument to fully offset the supply-side disturbance. This result follows Benigno and Woodford (2003), where the optimal distorting tax rate in a New Keynesian setting adjusts to perfectly offset the supply-side shock. The central bank can then focus on offsetting demand-side disturbances in a manner that completely stabilizes inflation.

This is the global minimum of the social loss and represents the case where two separate policymakers are given "correct" mandates. That is, there exists two appropriate policy control variables for two distortions. When these tools are optimally employed, social loss is minimized at zero. Notice that in this case, neither policymaker had minimizing the social loss function as their mandates, but they jointly achieve the global minimum of the social loss criterion.

\section{$5 \quad$ Idiosyncratic Policy Objectives}

The fact that giving a policymaker the maximization of social welfare may not be optimal has been known since the work of Kydland and Prescott (1977) on time inconsistency, but the mechanism we highlight is fundamentally different. Here the problem is not that the central bank cannot commit to pursuing the policy it promises today. In fact, the problem is that because the central bank will pursue the objective in a time-consistent manner, other policymakers are freed to pursue their own, possibly more narrow, objectives. This is the key concern of this paper.

The issue arises when policymakers have terms in their loss function not contained in the social objective function. Policy preferences unique to a particular policy making body could reflect an array of factors outside social welfare. For example, 
desire for fiscal expansion or austerity, "inside" lags associated with challenges in adjusting tax rates are factors that pertain to fiscal policy ${ }^{3}$ If the central bank's loss function remains (5)-a pure inflation targeter-then these other concerns manifest themselves by diminishing the extent to which the tax rate adjusts to offset the supply-side shock.

To illustrate our case, modify the fiscal authority's loss function to include other terms that do not appear in the social loss function as follows

$$
L_{t}^{F}=E_{t} \sum_{i=0}^{\infty} \beta^{i}\left(x_{t+i}^{2}+\lambda^{F} \tau_{t+i}^{2}\right)
$$

which reflects a desire to keep the tax rate close to a target rate that the fiscal authority has in mind. The resulting rule for the optimal tax rate is as follows

$$
\tau_{t}=\frac{\psi}{\kappa \lambda^{F}} x_{t}
$$

reflecting how a fiscal authority placing relatively high weight on being close to the target tax rate (i.e. relatively high $\lambda^{F}$ ) makes only modest adjustments to the tax rate in response to variations in the output gap. The rule can also be expressed in terms of shocks,

$$
\tau_{t}=-\frac{\psi}{\kappa^{2} \lambda^{F}+\psi^{2}} \varepsilon_{t}
$$

If $\lambda^{F}>0$, then the fiscal authority's concern for some target level of tax rates results in moving the equilibrium away from the social optimum. The stronger this concern, the further the policy pulls the equilibrium away from the social optimum.

Instead of strict inflation targeting, if the central bank includes the output gap in its objective with weight $\lambda^{C B}$, then the fiscal authority optimally sets its instrument according to

$$
\tau_{t}=\frac{\kappa \psi}{\lambda^{F}\left(\kappa^{2}+\lambda^{C B}\right)} x_{t}
$$

illustrating that if the central bank attaches weight to output fluctuations $\left(\lambda^{C B}>0\right)$, even in a way that aligns its loss function with society $\left(\lambda^{C B}=\lambda^{S}\right)$, the optimal fiscal

\footnotetext{
${ }^{3}$ These inside lags can also be thought of as equilibrium outcomes resulting from a game played between policymakers rather than being purely exogenous. That is, if fiscal policy does not have to be used for cyclical stabilization, it can afford to have inside lags.
} 
policy action is to reduce the sensitivity of its instrument to output fluctuations. In other words, the fiscal authority lets the central bank worry about output, as it turns focus to its other objective that is not included in social welfare. This dynamic is a fundamental reason why optimal monetary policy may not entail directly confronting the trade-off between the output gap and inflation.

In this setting, a key issue is whether given the social loss function (3), the central bank moves outcomes closer to minimizing the social loss by following strict inflation targeting, as in (5), or by adopting the social loss function, even though it may provide an incentive to the fiscal authority to stay away from an active role in output stabilization. Pure inflation targeting delivers perfectly stable inflation, with output following

$$
x_{t}^{I T}=-\frac{\kappa \lambda^{F}}{\kappa^{2} \lambda^{F}+\psi^{2}} \varepsilon_{t} .
$$

When the central bank adopts the social welfare function, output and inflation follow

$$
\begin{aligned}
x_{t}^{S} & =-\frac{\kappa \lambda^{F}\left(\kappa^{2}+\lambda^{S}\right)}{\left(\kappa^{2} \psi+\lambda^{F}\left(\kappa^{2}+\lambda^{S}\right)^{2}\right)} \varepsilon_{t}, \\
\pi_{t}^{S} & =\frac{\lambda^{S} \lambda^{F}\left(\kappa^{2}+\lambda^{S}\right)}{\left(\kappa^{2} \psi+\lambda^{F}\left(\kappa^{2}+\lambda^{S}\right)^{2}\right)} \varepsilon_{t} .
\end{aligned}
$$

The following show how output and inflation move when the fiscal authority places all the weight on hitting the target tax rate, with the central bank minimizing the social loss function,

$$
\begin{aligned}
\lim _{\lambda^{F} \rightarrow \infty} x_{t}^{S} & =-\frac{\kappa}{\left(\kappa^{2}+\lambda^{S}\right)} \varepsilon_{t} \\
\lim _{\lambda^{F} \rightarrow \infty} \pi_{t}^{S} & =\frac{\lambda^{S}}{\left(\kappa^{2}+\lambda^{S}\right)} \varepsilon_{t},
\end{aligned}
$$

which would be the results in a basic New Keynesian model without the distorting tax. This is the case where $\tau=0$ at all times and cyclical policy is carried out by the central bank exclusively. This limiting case highlights how a monetary authority willing to confront the trade-offs inherent in attempting to maximize social welfare absolves the fiscal authority from stabilizing output fluctuations (or more broadly, absolves other policymakers from addressing inefficiencies) that they can control. 
Still, the question remains under what conditions the monetary authority maximizes social welfare by pursuing pure inflation targeting, as opposed to adopting the social loss function. To address this issue, we apply some conventional parameter values to the model and evaluate whether the following criteria

$$
\operatorname{var}\left(\pi^{I T}\right)+\lambda^{S} \operatorname{var}\left(x^{I T}\right)<\operatorname{var}\left(\pi^{S}\right)+\lambda^{S} \operatorname{var}\left(x^{S}\right)
$$

holds for various combinations of $\lambda^{S}$ and $\lambda^{F}$. The right-hand side of the inequality corresponds to the unconditional loss when the central bank uses the social welfare function. The left-hand side also is the unconditional loss evaluated using social welfare, but under strict inflation targeting. In the latter case $\operatorname{var}\left(\pi^{I T}\right)=0$, hence the condition we check is

$$
\lambda^{S} \operatorname{var}\left(x^{I T}\right)<\operatorname{var}\left(\pi^{S}\right)+\lambda^{S} \operatorname{var}\left(x^{S}\right)
$$

Consider first the case when the fiscal authority places relatively low weight on the target tax rate, using its instrument relatively aggressively to offset supply-side shocks. In this case, as is shown in Figure 1, the monetary authority can reinforce this behavior by adopting pure inflation targeting, resulting in overall lower social loss than if it were to adopt the social loss function. The intuition for this result rests with equation (10), as it shows the fiscal authority will adjust the tax rate more aggressively in response to output fluctuations if the central bank is primarily focused on inflation. That is, the fiscal authority takes more ownership for output stabilization and behaves accordingly. This results in a modest cost for the fiscal authority, but inflicts no costs in the context of the social welfare objective. As a result, an inflation targeting central bank shifts the burden of output stabilization towards the fiscal authority, which has an effective instrument to stabilize output. The combination under inflation targeting is overall welfare improving.

Alternatively, Figure 2 shows a case when the fiscal authority places more weight on its tax smoothing objective. In this case, the fiscal authority is already too focused on its own objective, so the central bank increases overall social loss by focusing narrowly on strict inflation targeting. The fiscal authority is relatively too insensitive

\footnotetext{
${ }^{4}$ Parameter values are set as so the steady-state markup is $20 \%$ above marginal cost, the steady state tax rate is $\tau=.1, \sigma=1$ and the cost of price adjustment is set so that $\kappa=.1$ in the scenario with the relatively steep Phillips curve and $\kappa=.05$ in the case when it's relatively flat.
} 
to output loss, so the central bank cannot provide a sufficient incentive to induce fiscal policy to do what is socially desirable. By focusing heavily (or only) on inflation, the central bank can again shift some of the burden of output stabilization to the fiscal authority. But the action taken by the fiscal authority is not enough, from a social welfare perspective, to justify the central bank not addressing the output gap itself.

To more broadly illustrate situations when pure inflation targeting is optimal, Figure 3 shows the trade-offs in optimal policy design. In cases where the fiscal authority places relatively low weight on fiscal objectives outside of output stabilization (i.e. $\lambda^{F}$ is near zero), the central bank may raise social welfare via pure inflation targeting. When the fiscal authority puts too little relative weight on output stabilization, she cannot be incentivized enough to act to close the output gap, hence it is socially desirable to have the central bank address both output gap and inflation: $5^{5}$

The desirability of strict inflation targeting also hinges on the structure of the economy. Figure 4 shows conditions when strict inflation targeting is socially optimal under a relatively flat Phillips curve. In this case, monetary policy needs to adjust the output gap more forcefully to stabilize inflation. The additional volatility in output induces welfare losses that, relative to economies with a steeper Phillips curve, often makes strict inflation target welfare reducing. The exception, however, is when the fiscal authority attaches little weight to its idiosyncratic objective, which then allows for the clean separation of objectives and instruments.

While these examples take the objective functions of the two policymakers as independent of each other, an alternative way of highlighting our concern is to think of the social loss being shared by the two policymakers. For example, assume the social loss function is as in (3), but that the loss functions of the two policymakers are

$$
\begin{aligned}
L_{t}^{C B} & =E_{t} \sum_{i=0}^{\infty} \beta^{i}\left(\pi_{t+i}^{2}+\lambda^{C B} x_{t+i}^{2}\right), \\
L_{t}^{F} & =E_{t} \sum_{i=0}^{\infty} \beta^{i}\left(\left(\frac{\lambda^{S}-\lambda^{C B}}{\lambda^{S}}\right) x_{t+i}^{2}+\left(1-\left(\frac{\lambda^{S}-\lambda^{C B}}{\lambda^{S}}\right)\right) \tau_{t+i}^{2}\right) .
\end{aligned}
$$

\footnotetext{
${ }^{5}$ This of course assumes the relative weights of output gap and tax smoothing in the fiscal policy maker's loss function are exogenous. Below we discuss the case where the central bank and the fiscal authority share the the loss from output gap so that when the central bank assumes less of the output gap mandate, the fiscal policy maker assigns proportionately more weight to it.
} 
This approach explicitly builds in an understanding on the part of the fiscal authority that the greater focus on the output mandate from the central bank (i.e. higher settings for $\lambda^{C B}$ ) relative to society's preference, the more the fiscal authority can focus on its competing objective. In this formulation, the central bank adopting the social loss function $\left(\lambda^{C B}=\lambda^{S}\right)$ is clearly not in society's best interest, as the fiscal authority will then only care about its private objectives. On the other hand, if the central bank does not volunteer for any output related mandates $\left(\lambda^{C B}=0\right)$, then the entire loss due to output gap fluctuations is born by the fiscal authority, who in this case follows socially optimal policies and unconditional welfare reaches its global maximum.

Another implication of the above formulation is that the more weight society places on output gap fluctuations, the more is to be gained if the monetary authority adopts strict inflation targeting. Strict targeting would lead to a clean separation between objectives and instruments of the two policymakers, since the fiscal authority would focus on perfectly offsetting the disturbance to the Phillips curve, while monetary policy can perfectly offset shocks impinging on the Euler equation. This separation returns us to the initial arrangement were each policy authority is given "correct" mandates.

In these examples, where a fiscal policymaker has private objectives, but also cares sufficiently about social welfare, pure inflation targeting by the central bank helps align the behavior of the fiscal authority with social preferences. Of course, as we have seen, inflation targeting may not always be optimal. If the fiscal authority places a substantial amount of weight on its own objectives, monetary policy simply cannot get it to pay enough attention to relevant objects in the social welfare function, such as output gap stabilization.

From this perspective, a fiscal policy that places high weight on factors not included in the social loss function may reflect substantial "inside" lags. In practice, Blinder (2006) discusses how such lags reflect the time between when fiscal policymakers acknowledge the need for some action and the time it takes for policies to be implemented. In terms of the model, inside lags may appear to reflect a preferred tax rate, but in practice may capture the challenges associated with implementing fiscal reforms due to political considerations, or administrative time required to disburse funds and change tax withholding schedules. Interpreted this way, preferred 
tax rates would reflect exogenous constraints on the fiscal authority and not socially undesirable private concerns.

Whether such lags, or other ancillary policymaker concerns are exogenous or endogenous matters. We are used to thinking of central banks as the cyclical policymakers because of the slowness in implementing fiscal policy changes. However, this may be the observed result of the game between policymakers, rather than a constraint imposed by nature. One can imagine an alternative environment where the central bank moves slowly due to the long and variable lags of monetary policy effectiveness, and fiscal policy is nimble because someone has to address the cyclical policy needs.

While large inside lags for fiscal policy may call for a monetary policy that does adopt the social welfare loss, clearly an endogeneity issue arises. If the lags are endogenous, monetary policy attempting to address all cyclical concerns may not motivate other policymakers to address the road blocks that generate such inside lags. As a result, the fiscal authority's advantage is strengthened from the standpoint of being able to pay less attention to shocks, since they will be addressed by monetary policy, and allow it to shift weight towards its own particular objectives ${ }^{6}$

While we make our point in a simple, stylized model, the point is very general. The world is a multiple objective, multiple policymaker world. Policy makers have their own objectives and behave strategically. If one policymaker volunteers for the responsibility for multiple objectives, either due to the desire to be more important or due to lack of appropriate policies from other policymakers, the equilibrium outcomes may be suboptimal by the social welfare metric.

\section{Discussion}

The argument in this paper is motivated by a macroeconomic policy concern. If policy makers do not sufficiently internalize the welfare effects of their actions, in particular if another policymaker is seen as responsible for those outcomes, then they may choose socially suboptimal policies.

\footnotetext{
6 "First mover advantage" and "leader/follower" are terminology of sequential games. While the model we present is technically not sequential, the analogy is apt. We will turn to the sequential game analogy again in the general discussion below.
} 
As a recent example from the US, aggressive monetary actions from the Federal Reserve, both in terms of balance sheet policies and forward guidance, were tailored toward concerns about improving labor market conditions, though within a context of price stability. During such actions, however, fiscal policy underwent a significant tightening. For example, an estimate from the Brookings Institute has fiscal policy restraining real GDP growth by about 1 percentage point starting in 2011 through 2014.7 While it is difficult to determine whether fiscal policies would have been different if US monetary policy had been less accommodative, monetary policy actions certainly incorporated the weight tighter fiscal policy was exerting on the outlook. The FOMC statement from June 2013, for example, explicitly states that "fiscal policy is restraining growth." A monetary policy mandated to pursue both price stability and full employment, as is the Federal Reserve, may not have many alternatives in the face of such fiscal restraint. The question posed in this paper is whether such fiscal restraint would arise under the understanding by fiscal authorities that the central bank would not undertake easier policy to compensate.

We think of this as a general policy concern of increasing importance, as central banks are trying to address ever increasing loads of policy burdens. The model we presented above suggests that assigning the social welfare as the mandate to the central bank may not be optimal as it may distort the incentives of other policymakers. There are several ways to interpret our argument and tie it to the literature.

An obvious starting point is time inconsistency (Kydland and Prescott (1977)). While time inconsistency is effectively a game the central bank plays with the public (and its future self) over time, here we have a game between multiple policymakers within a single period. In this sense our work is closer to that of Dixit and Lambertini (2003) who study monetary and fiscal policy interactions in a time inconsistency setting. Although the mechanisms are different, the understanding is similar, the game entails strategic behavior of policymakers and given strategic behavior it may be optimal not to give the central bank social welfare as the objective. In fact, Rogoff (1985) had shown that a central banker who puts more weight (than social welfare does) on inflation maximizes welfare. Here we show that a central banker who puts similarly high weight on inflation again maximizes welfare, not by making the public take the socially desirable decision, but by making the other policymakers

\footnotetext{
${ }^{7}$ See http://www.brookings.edu/research/interactives/2014/fiscal-barometer.
} 
take socially desirable actions.

Another way of thinking of our argument is in terms of a sequential game. This is technically not correct in the context of the model we presented (the model is simultaneous), but the analogy is helpful. One may as well think of the setting where a policymaker moves first and a second policymaker moves next, trying to maximize its objective. If one of these policymakers has distortionary terms in her objective function, it may be preferable to shift the social welfare burden to that policymaker (make that policymaker move last) so that the relative weight of the distortion in her decision making is minimized. Whether this would improve welfare depends on how sensitive the other policymaker will be to this incentive, as discussed in section 5. In general, who goes first matters. A setting where fiscal policy moves last leaves the central bank with a different, and likely socially worse, set of constraints. Consequently, central banks need to remain attuned to how their policies and objectives may spill over into actions of other policy agencies before accepting the job of policymaker of last resort. Given the nature of the game, inflation targeting is the preferable approach either when society places relatively high weight on price stability or the non-monetary policy agency places sufficiently high weight on output stabilization.

In this sense, our results are bolstered by those of Walsh (2015), who considers the optimality of flexible inflation targeting when a central bank is pursuing multiple objectives. His concern is not interactions among multiple policymakers, nonetheless, in many circumstances, he shows strict inflation targeting comes remarkably close to maximizing social welfare. This result may be due to small welfare costs that arise from non-inflation objectives, such as exchange rate volatility or fluctuations in unemployment; or, fluctuations in non-inflation objectives may create welfare costs, but monetary policy is not the most effective instrument to address the distortions. Similarly, in Ravenna and Walsh (2012), a steady-state inefficiency exists in the labor market that requires a relatively large tax to correct, hence is not something monetary policy can effectively address. Any attempt to use monetary policy to offset this inefficiency creates an unfavorable trade-off for monetary policy that generates welfare losses relative to strict inflation targeting. We have a fundamentally different policy focus and mechanism in mind, but see these results as supporting our view that in many circumstances giving the central bank too broad a mandate may be suboptimal.

The example we worked with in this paper is a game between the monetary and 
fiscal policymakers. This can be thought of as a fiscal dominance story. Although more prevalent in the emerging markets literature, fiscal dominance has a long history in the analysis of advanced economies as well, leading to the fiscal theory of the price level. In work most relevant for our argument, building on the framework of Leeper (1991), Davig and Leeper (2011) illustrate that competing policy choices can be forced to a head if an economy reaches its fiscal limit, which is the point where tax rates can no longer rise and government purchases can no longer be reduced to stabilize debt dynamics. At this point, either transfer payments to households must be cut, the fiscal authority defaults on its outstanding debt or monetary policy capitulates by doing whatever it takes to stabilize debt dynamics, which is to allow higher inflation.

Thus, the scenario applies to debt-laden countries that have hit the limit of their borrowing capacity and are faced with difficult choices. A credible inflation targeting regime can take the monetary policy solution off the table, forcing the fiscal authority's hand to make adjustments that result in stabilizing debt prior to facing the immediate and painful policy choices that are only available at the fiscal limit. Opening the door to a monetary solution, however, can incentivize the fiscal authority to postpone choices that result in rising debt levels, leading to socially suboptimal equilibria, similar to what we observe in our model.

The examples have all been couched in terms of competing domestic policy authorities, though they also pertain to international monetary policy coordination. Consider a two-country model where one policymaker cares about global welfare and the other cares only about national welfare. The second policymaker may feel compelled to undertake beggar-thy-neighbor policies that cannot be undone by the first policymaker. Of course, not all international policy games are examples for our argument-it is not surprising that countries may strategically engage in competitive devaluations which reduce global welfare, for example. A good open economy example for our case is the lender of last resort function of the IMF, which is presumably trying to maximize global welfare but may also be providing a moral hazard problem for the policymakers of the countries that can count on IMF loans when things go badly (Bulow and Rogoff (1988)).

While we focus on an issue with clear policy relevance, the policy advice arising from our argument is not obvious. The examples in the paper suggest that a natural division of policy labor is for the central bank to care about inflation, leaving the other 
policy authorities to focus on objectives well-suited to their instruments. Key to our argument is that if the central bank takes on additional mandates, other policymakers may face incentives not in line with social welfare, hence central bank mandate creep may be welfare detrimental. However, this does not answer the question of how to move to the good equilibrium if a country is stuck in the bad one.

If other policymakers are behaving socially suboptimally, it would entail a very large welfare cost if the central bank does not try to maximize social welfare to induce those policymakers to move to the good policy equilibrium. This is a general problem in too-big-to-fail situations, where the problem is best solved before it arises and the policy options are limited once the choice is between allowing catastrophe now and providing bad incentives for the future.

\section{Conclusions}

The optimal macroeconomic policy literature focuses on monetary policy and especially during the recent crisis monetary policy became the policy tool to address all economic ailments. While it is clearly optimal for monetary policy to pick up policy slack if other policymakers are not doing their jobs for various reasons, we highlight the problem that this makes it easier and more likely for those other policymakers not to do their jobs. We should be cognizant of this cost of equating optimal policy with optimal monetary policy.

While we point out the problem, we are short of offering a solution. Monetary policy not behaving as the policymaker of last resort and allowing a sizable welfare loss to incentivize other policymakers to do their jobs is a very costly way of realigning policymaker mandates. We see highlighting the problem as the first step. Hopefully thinking about ways to alleviate it will follow. 


\section{A Appendix}

\section{A.1 Households and Monopolistically Competitive Firms un- der a Value-Added Tax}

Households choose sequences of $C_{t}, N_{t}$, and $B_{t}$ to maximize utility given by

$$
E_{0} \sum_{t=0}^{\infty} \beta^{t}\left[\frac{C_{t}^{1-\sigma}}{1-\sigma}-\frac{N_{t}^{1+\mu}}{1+\mu}\right]
$$

subject to

$$
C_{t}+\frac{B_{t}}{P_{t}}=T_{t}+\frac{W_{t}}{P_{t}} N_{t}+\left(1+i_{t-1}\right) \frac{B_{t-1}}{P_{t}}+\frac{D_{t}}{P_{t}},
$$

where $C_{t}$ denotes real consumption, $B_{t}$ nominal bonds, $P_{t}$ the price level, $T_{t}$ lumpsum taxes, or rebate, $W_{t}$ nominal wages, $N_{t}$ labor supply, $i_{t}$ the nominal interest rate and $D_{t}$ nominal dividends. The consumption bundle is a CES aggregate given by

$$
C_{t}=\left[\int_{0}^{1} c_{t}(i)^{(\epsilon-1) / \epsilon} d i\right]^{\epsilon /(\epsilon-1)}
$$

Linearization of the households optimality condition for consumption yields (2).

A monopolistically competitive firm $i$ maximizes the present value of real dividends

$$
\Pi_{i t}=E_{t} \sum_{j=0}^{\infty} \beta^{j} \lambda_{t+j} \frac{D_{i t+j}}{P_{t+j}},
$$

subject to the following demand curve

$$
Y_{i t}=\left(\frac{P_{i t}}{P_{t}}\right)^{-\epsilon} Y_{t}
$$

and production function

$$
Y_{i t}=A_{t} N_{i t}
$$

where $A_{t}$ represents economy-wide total factory productivity and $\frac{\psi}{2}\left(\frac{P_{i t}}{P_{i t-1}}-\pi\right)^{2} Y_{t}$ is the quadratic cost of price adjustment. The government runs a period-by-period balanced budget, so rebates all proceeds from the tax back to households via a lump- 
sum transfer. After taking into account a value-added tax, period profits are defined as

$$
\frac{D_{i t}}{P_{t}}=\frac{P_{i t}}{P_{t}} Y_{i t}\left(1-\tau_{t}\right)-\Phi_{t} Y_{i t}-\frac{\nu}{2}\left(\frac{P_{i t}}{\Pi P_{i t-1}}-1\right)^{2} Y_{t},
$$

where $\Pi$ is the steady-state inflation rate and $\Phi_{t}$ is real marginal cost. The firm's first-order condition is given by

$$
\begin{aligned}
0= & (1-\epsilon) \lambda_{t}\left(\frac{P_{i t}}{P_{t}}\right)^{-\epsilon}\left(\frac{Y_{t}}{P_{t}}\right)\left(1-\tau_{t}\right)+\epsilon \lambda_{t} \Phi_{t}\left(\frac{P_{i t}}{P_{t}}\right)^{-1-\epsilon}\left(\frac{Y_{t}}{P_{t}}\right) \\
& -\nu \lambda_{t}\left(\frac{P_{i t}}{\Pi P_{i t-1}}-1\right)\left(\frac{Y_{t}}{\Pi P_{i t-1}}\right) \\
& +\beta E_{t}\left[\psi \lambda_{t+1}\left(\frac{P_{i t+1}}{\Pi P_{i t}}-1\right)\left(\frac{P_{i t+1} Y_{t+1}}{\Pi P_{i t}^{2}}\right)\right],
\end{aligned}
$$

which after imposing a symmetric equilibrium, so $P_{i t}=P_{t}$, can be rewritten as follows

$$
\begin{aligned}
0= & (1-\epsilon) \lambda_{t}\left(1-\tau_{t}\right)+\epsilon \lambda_{t} \Phi_{t} \\
& -\nu \lambda_{t}\left(\frac{\Pi_{t}}{\Pi}-1\right)\left(\frac{\Pi_{t}}{\Pi}\right) \\
& +\beta E_{t}\left[\psi \lambda_{t+1}\left(\frac{\Pi_{t+1}}{\Pi}-1\right)\left(\frac{\Pi_{t+1} Y_{t+1}}{\Pi Y_{t}}\right)\right],
\end{aligned}
$$

where $\Pi_{t}=P_{t} / P_{t-1}$. Steady-state marginal costs are given by

$$
\Phi=\frac{(\epsilon-1)\left(1-\tau_{t}\right)}{\epsilon}
$$

and the linearized Phillips curve is

$$
\widehat{\pi}_{t}=\beta E_{t} \widehat{\pi}_{t+1}+\frac{(\epsilon-1)(1-\tau)}{\nu} \widehat{\phi}_{t}+\frac{\tau(\epsilon-1)}{\nu} \widehat{\tau}_{t},
$$

where $\widehat{\phi}_{t} \equiv \log \Phi_{t}-\log \Phi, \widehat{\pi}_{t} \equiv \log \Pi_{t}-\log \Pi$, and $\widehat{\tau}_{t} \equiv \log \tau_{t}-\log \tau$. Variables without time subscripts denote steady-state values. 


\section{A.2 Flexible Price Equilibrium}

If prices are fully flexible, the desired price would be a constant markup, $\theta$, over real marginal cost after adjusting for the time-varying tax rate,

$$
\left(\frac{P_{i t}}{P_{t}}\right)=\frac{\theta}{\left(1-\tau_{t}\right)} \Phi_{t}
$$

In equilibrium, $P_{i t}=P_{t}$, real marginal cost then varies with the tax rate as follows

$$
\Phi_{t}=\frac{\left(1-\tau_{t}\right)}{\theta}
$$

From the firm's cost minimization problem, real marginal costs can also be expressed as

$$
\Phi_{t}=\frac{\left(W_{t} / P_{t}\right)}{A_{t}}
$$

which implies

$$
\frac{W_{t}}{P_{t}}=\frac{\left(1-\tau_{t}\right) A_{t}}{\theta}
$$

To then express the linearized Phillips curve A.7 in terms of an output gap, first take the household's optimality condition governing labor supply

$$
\frac{W_{t}}{P_{t}}=C_{t}^{\sigma} N_{t}^{\mu}
$$

then equate expressions for real wages,

$$
\frac{\left(1-\tau_{t}\right) A_{t}}{\theta}=C_{t}^{\sigma} N_{t}^{\mu}
$$

and write in log deviations from its steady state,

$$
\widehat{a}_{t}=\sigma \widehat{c}_{t}+\frac{\tau}{1-\tau} \widehat{\tau}_{t}+\mu \widehat{n}_{t}
$$

where $\widehat{x}_{t} \equiv \log X_{t}-\log X$. Using this relation with the linearized production function and imposing $\widehat{y}_{t}=\widehat{c}_{t}$ yields

$$
\widehat{y}_{t}^{f}=\frac{(1+\mu)}{(\sigma+\mu)} \widehat{a}_{t}-\frac{\tau}{(1-\tau)(\sigma+\mu)} \widehat{\tau}_{t},
$$


where $\widehat{y}_{t}^{f}$ is the log deviation of output under fully flexible prices. Rewriting A.10 allowing for time-varying markups yields

$$
\begin{aligned}
\widehat{\phi}_{t} & =\left(\widehat{w}_{t}-\widehat{p}_{t}\right)-\left(\widehat{y}_{t}-\widehat{n}_{t}\right)+\frac{\tau}{1-\tau} \widehat{\tau}_{t} \\
& =\sigma \widehat{y}_{t}+\mu\left(\widehat{y}_{t}-\widehat{a}_{t}\right)-\widehat{a}_{t}+\frac{\tau}{1-\tau} \widehat{\tau}_{t} \\
& =(\sigma+\mu) \widehat{y}_{t}-(1+\mu) \widehat{a}_{t} \\
& =(\sigma+\mu)\left[\widehat{y}_{t}-\frac{(1+\mu)}{(\sigma+\mu)} \widehat{a}_{t}+\frac{\tau}{(1-\tau)(\sigma+\mu)} \widehat{\tau}_{t}\right] \\
& =(\sigma+\mu)\left[\widehat{y}_{t}-\widehat{y}_{t}^{f}\right]
\end{aligned}
$$

which allows the Phillips curve relation to be rewritten in terms of a flexible price output gap,

$$
\widehat{\pi}_{t}=\beta E_{t} \widehat{\pi}_{t+1}+\frac{(\epsilon-1)(1-\tau)}{\nu}(\sigma+\mu) x_{t}+\frac{\tau(\epsilon-1)}{\nu} \widehat{\tau}_{t},
$$

where $x_{t} \equiv\left[\widehat{y}_{t}-\widehat{y}_{t}^{f}\right]$.

\section{A.3 Optimal Policy Under "Correct" Objectives}

When the monetary authority is a pure inflation targeter, the optimal interest rate rule is derived by solving the following

$$
\min _{x_{t}} \pi_{t}^{2}
$$

subject to

$$
\pi_{t}=\beta E_{t} \pi_{t+1}+\kappa x_{t}+\psi \tau_{t}+\varepsilon_{t}
$$

where expectations are taken as given, so the policy reflects discretion in the sense that the central bank is not committing to a future course of action (but note that neither the social loss function nor any central bank loss function in our model will lead to time inconsistency under discretion). The problem provides a standard reaction function, derived by substituting the first-order condition $\pi_{t}=0$ back into the Phillips curve

$$
x_{t}=-\frac{\psi \tau_{t}+\varepsilon_{t}}{\kappa}
$$


To express this rule in terms of the interest rate, substitute back into the consumption Euler equation to yield

$$
i_{t}=\frac{\sigma}{\kappa}\left(\varepsilon_{t}+\psi \tau_{t}\right)+\sigma u_{t},
$$

where the central bank takes the tax rate as given when setting policy.

To derive (7), the fiscal authority solves

$$
\min _{\tau_{t}} x_{t}^{2}
$$

subject to

$$
x_{t}=E_{t} x_{t+1}-\sigma^{-1}\left(i_{t}-E_{t} \pi_{t+1}\right)+u_{t},
$$

and $A .13$, which can be expressed as

$$
\min _{\tau_{t}}\left(-\sigma^{-1}\left(\frac{\sigma}{\kappa}\left(\varepsilon_{t}+\psi \tau_{t}\right)+\sigma u_{t}\right)+u_{t}\right)^{2}
$$

yielding the optimal rule (7),

$$
\tau_{t}=-\frac{1}{\psi} \varepsilon_{t}
$$

The important difference between the monetary and fiscal authority's problems is that monetary policy takes $\tau_{t}$ as given, whereas the fiscal authority incorporates the interest rate response into how it sets $\tau_{t}$.

\section{A.4 Optimal Policy Under Idiosyncratic Objectives}

When the fiscal authority adopts a preference for tax smoothing, the loss function becomes

$$
\min _{\tau_{t}} x_{t}^{2}+\lambda^{F} \tau_{t}^{2}
$$

After substituting in the consumption Euler equation and the central bank's optimal rule under strict inflation targeting, the problem is recast as follows

$$
\min _{\tau_{t}}\left(-\sigma^{-1}\left(\frac{\sigma}{\kappa}\left(\varepsilon_{t}+\psi \tau_{t}\right)+\sigma u_{t}\right)+u_{t}\right)^{2}+\lambda^{F} \tau_{t}^{2}
$$


with the first-order condition given by

$$
\tau_{t}=\frac{\psi}{\kappa \lambda^{F}} x_{t}
$$

If the monetary authority adopts the social loss function, then the fiscal authorities problem becomes

$$
\min _{\tau_{t}}\left(-\sigma^{-1}\left(\frac{\kappa \sigma}{\kappa^{2}+\lambda^{S}}\left(\varepsilon_{t}+\psi \tau_{t}\right)+\sigma u_{t}\right)+u_{t}\right)^{2}+\lambda^{F} \tau_{t}^{2}
$$

so the first-condition is then

$$
\tau_{t}=\frac{\kappa \psi}{\lambda^{F}\left(\kappa^{2}+\lambda^{S}\right)} x_{t}
$$

\section{A.5 Equilibrium under strict inflation targeting}

When the central bank follows a strict inflation target and the fiscal authority has some preference for a target tax rate, the complete setting is given by

$$
\begin{aligned}
x_{t} & =E_{t} x_{t+1}-\sigma^{-1}\left(i_{t}-E_{t} \pi_{t+1}\right) \\
\pi_{t} & =\beta E_{t} \pi_{t+1}+\kappa x_{t}+\psi \tau_{t}+\varepsilon_{t} \\
\tau_{t} & =\frac{\psi}{\kappa \lambda^{F}} x_{t} \\
i_{t} & =\frac{\sigma}{\kappa}\left(\varepsilon_{t}+\psi \tau_{t}\right)+\sigma u_{t}
\end{aligned}
$$

To compute the solution, guess it takes the following form

$$
x_{t}=c_{x} \varepsilon_{t}, \pi_{t}=c_{\pi} \varepsilon_{t}, \tau_{t}=c_{\tau} \varepsilon_{t}, i_{t}=c_{i} \varepsilon_{t}
$$


Substituting back into the original system and collecting coefficients as follows yields the solution

$$
\left[\begin{array}{c}
c_{x} \\
c_{\pi} \\
c_{\tau} \\
c_{i}
\end{array}\right]=\left[\begin{array}{cccc}
1 & 0 & 0 & \frac{1}{\sigma} \\
-\kappa & 1 & -\psi & 0 \\
-\frac{\psi}{\kappa \lambda^{F}} & 0 & 1 & 0 \\
0 & 0 & -\psi & \frac{\kappa}{\sigma}
\end{array}\right]^{-1}\left[\begin{array}{l}
0 \\
1 \\
0 \\
1
\end{array}\right]=\left[\begin{array}{c}
-\kappa \frac{\lambda^{F}}{\psi^{2}+\kappa^{2} \lambda^{F}} \\
0 \\
-\frac{\psi}{\psi^{2}+\kappa^{2} \lambda^{F}} \\
\kappa \sigma \frac{\lambda^{F}}{\psi^{2}+\kappa^{2} \lambda^{F}}
\end{array}\right] .
$$

\section{A.6 Equilibrium when the central bank adopts the social welfare function as its objective}

When the central bank minimizes social loss and the fiscal authority has some preference for a target tax rate, the complete setting is given by

$$
\begin{aligned}
x_{t} & =E_{t} x_{t+1}-\sigma^{-1}\left(i_{t}-E_{t} \pi_{t+1}\right) \\
\pi_{t} & =\beta E_{t} \pi_{t+1}+\kappa x_{t}+\psi \tau_{t}+\varepsilon_{t} \\
\tau_{t} & =\frac{\kappa \psi}{\lambda^{F}\left(\kappa^{2}+\lambda^{S}\right)} x_{t} \\
i_{t} & =\frac{\kappa \sigma}{\kappa^{2}+\lambda^{S}}\left(\varepsilon_{t}+\psi \tau_{t}\right)
\end{aligned}
$$

To compute the solution, guess it takes the following form

$$
x_{t}=c_{x} \varepsilon_{t}, \pi_{t}=c_{\pi} \varepsilon_{t}, \tau_{t}=c_{\tau} \varepsilon_{t}, i_{t}=c_{i} \varepsilon_{t}
$$

Substituting back into the original system and collecting coefficients as follows yields the solution

$$
\left[\begin{array}{c}
c_{x} \\
c_{\pi} \\
c_{\tau} \\
c_{i}
\end{array}\right]=\left[\begin{array}{cccc}
1 & 0 & 0 & \frac{1}{\sigma} \\
-\kappa & 1 & -\psi & 0 \\
-\frac{\kappa \psi}{\lambda^{F}\left(\kappa^{2}+\lambda^{S}\right)} & 0 & 1 & 0 \\
0 & 0 & -\frac{\kappa \sigma \psi}{\kappa^{2}+\lambda^{S}} & 1
\end{array}\right]^{-1}\left[\begin{array}{c}
0 \\
1 \\
0 \\
\frac{\kappa \sigma}{\kappa^{2}+\lambda^{S}}
\end{array}\right]=\left[\begin{array}{c}
-\frac{\kappa \lambda^{F}\left(\kappa^{2}+\lambda^{S}\right)}{\left(\kappa^{2} \psi^{2}+\lambda^{F}\left(\kappa^{2}+\lambda^{S}\right)^{2}\right)} \\
\frac{\lambda^{S} \lambda^{F}\left(\kappa^{2}+\lambda^{S}\right)}{\left(\kappa^{2} \psi^{2}+\lambda^{F}\left(\kappa^{2}+\lambda^{S}\right)^{2}\right)} \\
-\frac{\psi \kappa^{2}}{\left(\kappa^{2} \psi^{2}+\lambda^{F}\left(\kappa^{2}+\lambda^{S}\right)^{2}\right)} \\
\frac{\sigma \kappa \lambda^{F}\left(\kappa^{2}+\lambda^{S}\right)}{\left(\kappa^{2} \psi^{2}+\lambda^{F}\left(\kappa^{2}+\lambda^{S}\right)^{2}\right)}
\end{array}\right]
$$




\section{References}

Adam, Klaus and Michael Woodford. 2013. "Housing Prices and Robustly Optimal Monetary Policy.". Working Paper, June.

Akkaya, Yıldız and Refet S. Gürkaynak. 2012. "Cari Açı, Bütçe Dengesi, Finansal İstikrar ve Para Politikası: Heyecanlı Bir Dönemin İzi." İktisat, İsletme ve Finans 27(315):93-119.

Benigno, Pierpaolo and Michael Woodford. 2003. Optimal Monetary and Fiscal Policy: A Linear-Quadratic Approach. In NBER Macroeconomics Annual 2003. Cambridge, MA: MIT Press.

Bernanke, Ben and Frederic S. Mishkin. 1997. "Inflation Targeting: A New Framework for Monetary Policy?" Journal of Economic Perspectives 11(Spring):97-116.

Blinder, Alan. 2006. The Case Against the Case Against Discretionary Fiscal Policy. In The Macroeconomics of Fiscal Policy, ed. G. Tootell R. Kopcke and R. Triest. MIT Press.

Bulow, Jeremy and Kenneth Rogoff. 1988. "Multilateral Negotiations for Rescheduling Developing Country Debt: A Bargaining-Theoretic Framework." IMF Staff Papers 35(December):644-657.

Corsetti, Giancarlo, Luca Dedola and Sylvain Leduc. 2010. Optimal Monetary Policy in Open Economies. In Handbook of Monetary Economics, Volume III, ed. B. M. Friedman and Michael. Woodford. Amsterdam: Elsevier Science Publishers, B.V.

Davig, Troy and Eric Leeper. 2011. "Temporarily Unstable Government Debt and Inflation." IMF Economic Review 59.

Dixit, Avinash and Luisa Lambertini. 2003. "Interactions of Commitment and Discretion in Monetary and Fiscal Policies." American Economic Review 93(5):1522-1542.

Gali, Jordi. 2014. "Monetary Policy and Rational Asset Price Bubbles." American Economic Review 104(3):721-752.

Giannoni, Marc P. and Michael Woodford. 2002. "Optimal Interest Rate Rules: I. General Theory.". NBER Working Paper No. 9419.

Gürkaynak, Refet S. 2015. Appropriate Policy Tools to Manage Capital Flow Externalities. In Taming Capital Flows, ed. Joseph Stiglitz and Refet S. Gürkaynak. London, England: Palgrave pp. 82-92.

Gürkaynak, Refet S., Zeynep Kantur, Anıl Taş and Seçil Yıldırım. 2015. "Monetary Policy in Turkey after Central Bank Independence." İktisat, Işletme ve Finans, forthcoming . 
Krause, Michael and Wolfgang Lemke. 2005. "Optimal Monetary Policy Response to Distortionary Tax Changes.". Working Paper.

Kydland, Finn and Edward C. Prescott. 1977. "Rules Rather Than Discretion: The Inconsistency of Optimal Plans." Journal of Political Economy 85:473-492.

Leeper, Eric M. 1991. "Equilibria Under 'Active' and 'Passive' Monetary and Fiscal Policies." Journal of Monetary Economics 27(1):129-147.

Orphanides, Athanasios. 2013. "Is Monetary Policy Overburdened?". BIS Papers, No. 435.

Ravenna, Federico and Carl E. Walsh. 2012. "Monetary Policy and Labor Market Frictions: A Tax Interpretation." Journal of Monetary Policy 59:180-195.

Rogoff, Kenneth. 1985. "The Optimal Degree of Commitment to an Intermediate Monetary Target." Quarterly Journal of Economics pp. 1169-1189.

Rotemberg, Julio J. and Michael Woodford. 1997. An Optimization-Based Econometric Framework for the Evaluation of Monetary Policy. In NBER Macroeconomics Annual 1997, ed. Ben S. Bernanke and Julio J. Rotemberg. Vol. 12 Cambridge, MA: MIT Press pp. 297-346.

Smets, Frank. 2014. "Financial Stability and Monetary Policy: How Closely Interlinked?" International Journal of Central Banking 10(2):263-300.

Svensson, Lars E.O. 2014. "To Lean or Not To Lean: The Swedish Experience.".

Walsh, Carl E. 2015. "Goals and rules in central bank design." International Journal of Central Banking, forthcoming . 


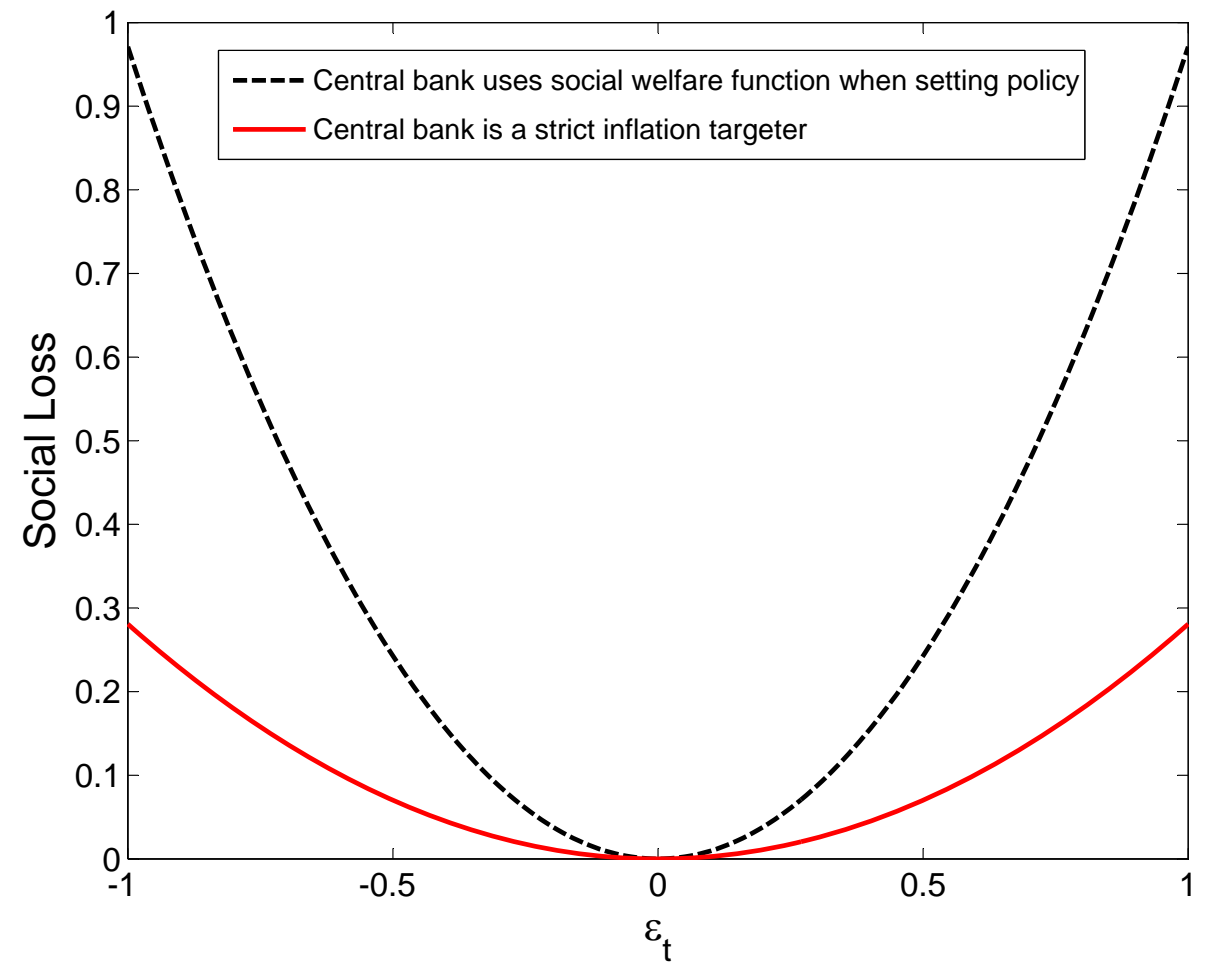

Figure 1: Social loss under a fiscal authority that places relatively low weight on hitting a target tax rate $\left(\lambda^{C B}=.5, \lambda^{F}=.001\right)$. 


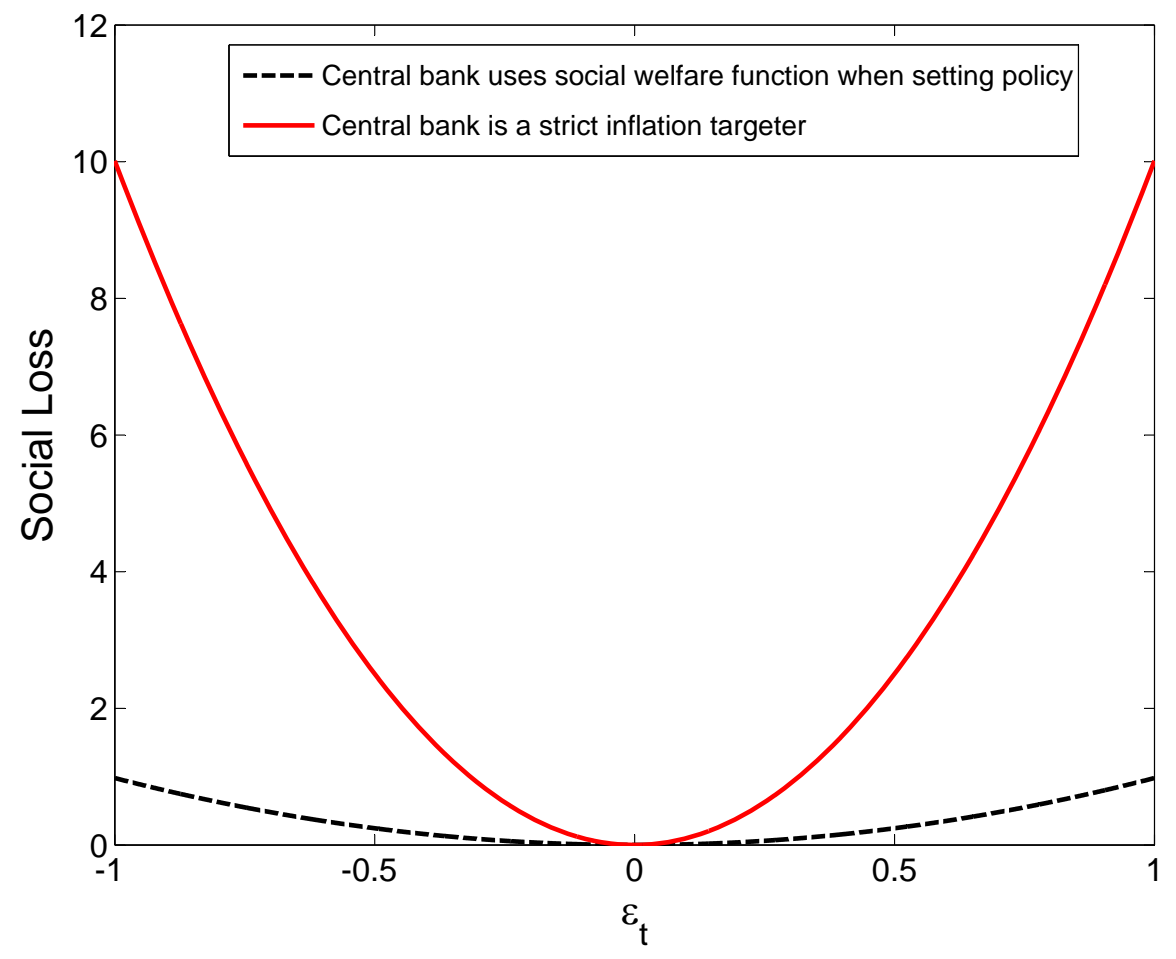

Figure 2: Social loss under a fiscal authority places relatively high weight on a target tax rate $\left(\lambda^{C B}=.5, \lambda^{F}=.01\right)$. 


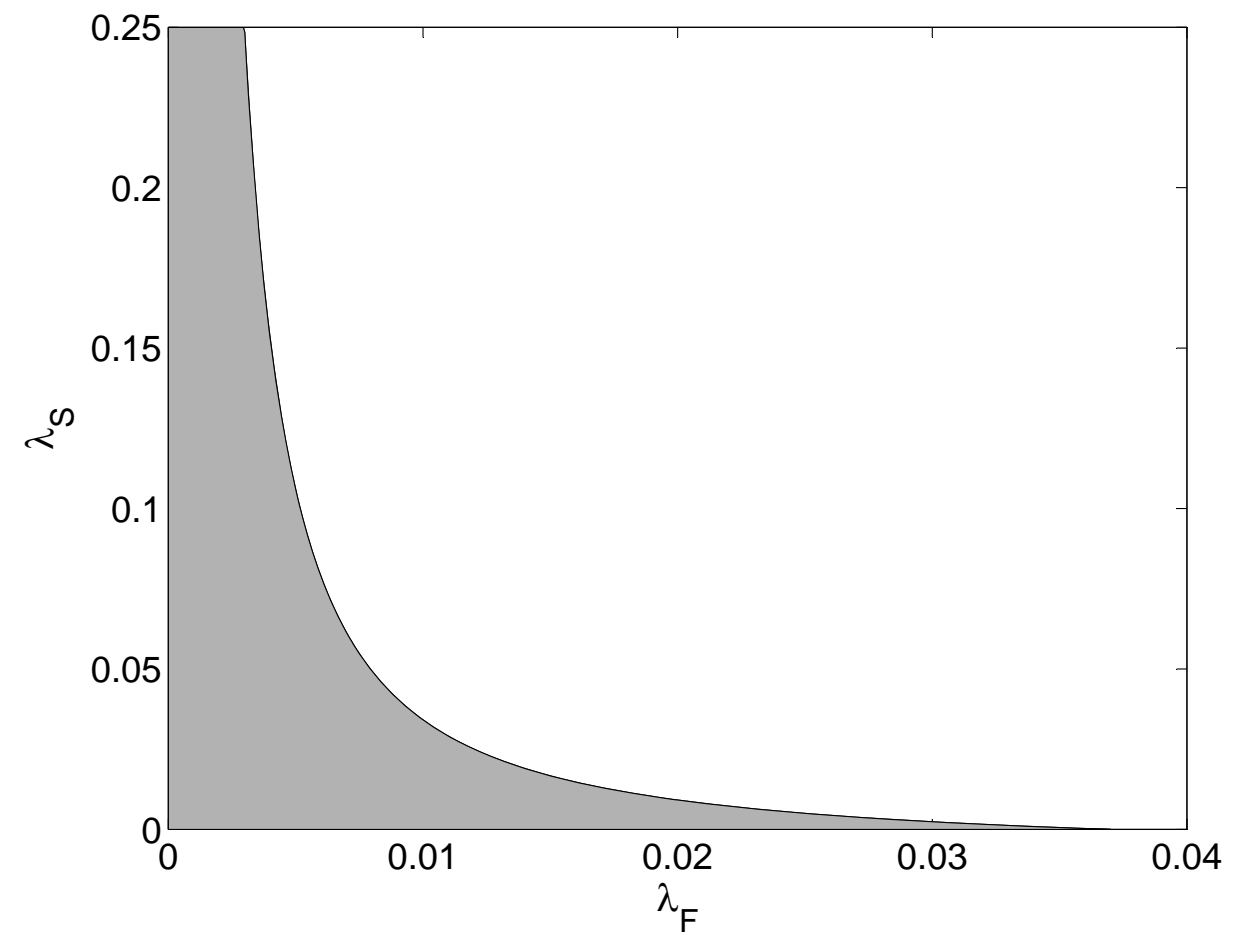

Figure 3: Monetary-Fiscal tradeoffs under relatively steep Phillips curve $(\kappa=.1)$ : The shaded area represents conditions when social welfare is higher under a pure inflation targeting regime. 


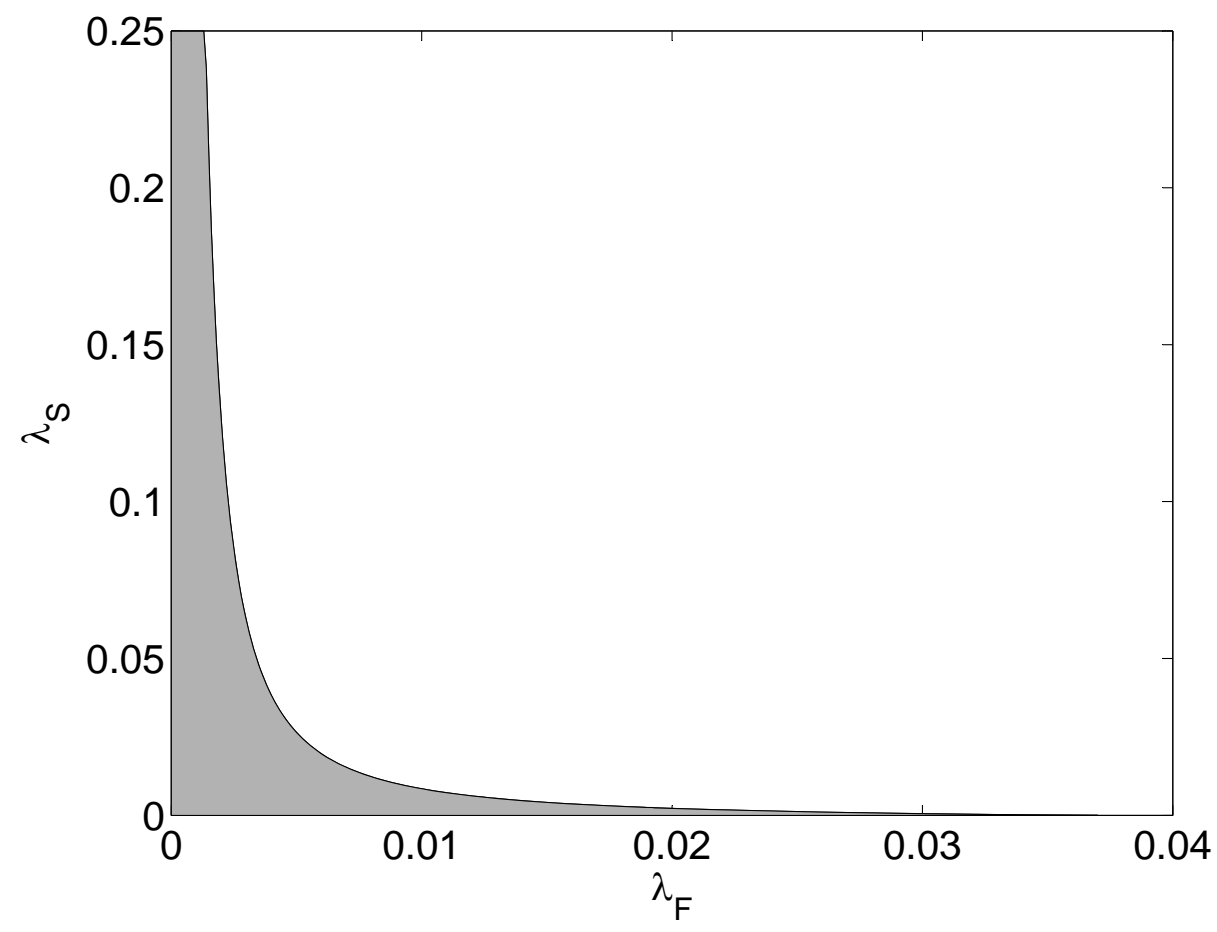

Figure 4: Monetary-Fiscal tradeoffs under relatively flat Phillips curve $(\kappa=.05)$ : The shaded area represents conditions when social welfare is higher under a pure inflation targeting regime. 